\title{
The Effect of Greenhouse Pollination Methods on Consumers' Willingness to Pay for Tomatoes in Japan
}

\author{
Takeshi Nishimura (D) \\ Faculty of Regional Management, Sanyo Gakuen University, 1-14-1 Hirai, Naka-ku, Okayama 703-8501, Japan \\ Corresponding author. Email: takenishi@gmail.com
}

\begin{abstract}
Since 2017, the Japanese government has been phasing out the use of non-native bumblebees as greenhouse tomato pollinators due to their ecological risks. We used an online questionnaire to investigate whether pollination methods affect consumers' willingness to pay (WTP) for tomatoes. We found that consumers valued the use of non-native bumblebees more than hormonal treatment and native more than non-native bees. Moreover, we found that informing consumers of the ecological risks increased WTP for native bumblebees and hormonal treatment. These results suggest that pollination method labeling may help protect ecosystems from the threat of non-native species.
\end{abstract}

Keywords: bumblebee; choice experiment; consumer; non-native species; pollination; tomato; willingness to pay

JEL Classifications: D12; Q18; Q57

\section{Introduction}

In greenhouse tomato production, employing bumblebees as pollinators has become common practice worldwide. In particular, Bombus terrestris (B. terrestris) is commercially reared on a large scale and has been used to pollinate tomatoes in various countries. In Japan, $B$. terrestris was introduced in earnest in 1992 and used by greenhouse tomato growers throughout Japan as a pollinator (Mitsuhata, 2000; Nishimura, 2010). Prior to the introduction of bumblebees, greenhouses frequently used plant growth regulators (also called "hormone sprays") for tomato pollination (Gosterit and Gurel, 2018). The introduction of bumblebees has freed tomato growers from labor-intensive pollination and enabled them to increase the sizes of their greenhouses (Nishimura, 2010; Velthuis and Doorn, 2006).

In addition to reducing labor for tomato growers, bumblebee pollination has more positive effects on tomato yields, size, weight, and seed counts than the honeybee and traditional vibration approaches to pollination used in England (Banda and Paxton, 1991). These positive effects were also observed in other countries, demonstrating that bumblebees are more efficient than vibration and plant growth regulators in greenhouse tomato production (Daşgan et al., 2004). Moreover, compared to hormonal treatment, pollination by bumblebees improves tomato quality. For example, the jelly inside the tomato fruit is enriched, the overall shape improves, the cavities decrease, the sugar content rises, and the vitamin C content increases (Gosterit and Gurel, 2018; Matsuura, 1993; Mitsuhata, 2018; Velthuis and Doorn, 2006).

Thus, $B$. terrestris has a significant impact on agricultural production, especially greenhouse tomato production, not only in European countries, such as Belgium and the Netherlands, but also in countries such as Chile, New Zealand, Turkey, South Korea, and Japan - broadly speaking, outside of Africa and North America, tomato growers benefit from B. terrestris

(c) The Author(s) 2021. Published by Cambridge University Press on behalf of the Southern Agricultural Economics Association. This is an Open Access article, distributed under the terms of the Creative Commons Attribution licence (http://creativecommons.org/licenses/by/4.0/), which permits unrestricted re-use, distribution, and reproduction in any medium, provided the original work is properly cited. 
pollination (Velthuis and Doorn, 2006). In 2016, the total area of greenhouse tomato production in Japan was 7,082.8 ha, and the total area of bumblebee use was 2,778.6 ha, of which the total area of B. terrestris was 2,264.8 ha (Ministry of Agriculture, Forestry and Fisheries, 2018). Regarding the total area, bumblebees pollinated $39.2 \%$ of greenhouse tomatoes, and $B$. terrestris pollinated $32.0 \%$ of greenhouse tomatoes.

However, Japanese ecologists worry about the ecological concerns posed by the importation of non-native bumblebees (Velthuis and Doorn, 2006). Findings regarding a naturalized colony of B. terrestris in Hokkaido, Japan, in 1996 prompted ecologists to discuss the potential damage to the domestic ecosystem that can occur when non-native bumblebees escape from tomato greenhouses to establish themselves and the consequent need for regulations regarding the species (Goka, 2010; Washitani, 1998). Some ecologists and civilian environmentalists have demanded a ban on the use of non-native bumblebees for pollination in the production of crops, especially tomatoes. However, tomato growers and agricultural organizations opposed the ban, citing significant consequences, such as that most of the growers may withdraw from tomato production since their economic survival will be severely hampered. Eventually, in 2006, the species was designated as an invasive alien species under the Invasive Alien Species Act in Japan, thus banning its use in principle. However, stakeholders argue that its use should still be permitted for academic research and occupation maintenance (Muto and Nishimura, 2014).

Since 2006, the use of $B$. terrestris has required permission from the Minister of Environment in accordance with the Invasive Alien Species Act of Japan. Tomato growers can use the species under the condition that they set up screens to prevent the bees from escaping greenhouses and properly dispose of used colonies. However, a moral hazard exists: tomato growers, once permitted, do not have sufficient incentives to obey these conditions because whether such growers' costly efforts continue is not observable by regulators (Nishimura, 2013; Nishimura and Muto, 2019). Therefore, as long as the Japanese government permits the use of non-native bumblebees, Japan is not immune to their ecological risks. Even after the Invasive Alien Species Act was enforced, studies maintain that the use of the species in Japan continues to pose various risks (Yoneda, Tsuchida, and Goka, 2008).

Although the Ministry of the Environment began studying approaches to regulating $B$. terrestris at an expert meeting in 2004, after its ecological risk became apparent, and eventually implemented the regulation described above, the Ministry of Agriculture, Forestry and Fisheries has been instructing tomato growers and agricultural organizations to switch to native bumblebees since 2005 (Niwase, 2005). In April 2017, the Ministry of the Environment and the Ministry of Agriculture, Forestry and Fisheries jointly compiled a "Policy on the Use of Alternative Species to Bombus terrestris" to promote the switch from B. terrestris to a species native to Japan, B. ignitus (Ministry of the Environment and Ministry of Agriculture, Forestry and Fisheries, 2017). This policy assumes that the most effective way to reduce ecological risk is to phase out the use of $B$. terrestris while taking care not to affect industry, especially agriculture, adversely. As Velthuis and Doorn (2006) point out, in the long term, Japan will likely ban the use of $B$. terrestris. In the short term, Japan hopes to halve the total shipment volume of B. terrestris (about 60,000 colonies, excluding Hokkaido, where there are no alternative species) by the end of 2020 . In recent years, the prospect of commercially rearing native bumblebee species has begun to emerge in Japan. However, approximately 60,000 colonies of $B$. terrestris were used between 2012 and 2017; it is unlikely that Japan will be able to halve this number by the end of 2020 because many growers are skeptical of whether native bumblebees perform as well as nonnative species (Ministry of the Environment, 2019).

Since no incentives exist to encourage tomato growers to switch from non-native to native bumblebees (Nishimura, 2010), it is unlikely that many will make the change. To remedy the current situation, researchers may turn to consumer support: if consumers support tomato growers who preserve domestic ecosystems, then they may actively purchase tomatoes pollinated by native species. 
This study investigates whether consumers' willingness to pay (WTP) for tomatoes changes when growers switch from non-native to native bumblebee pollinators. In particular, this study investigates whether using a label to indicate the pollination method of tomatoes sold at retail stores may affect consumers' WTP in a way that incentivizes growers' use of native bumblebees. Part of this inquiry involves uncovering whether there is a difference between WTP for pollination by non-native bumblebees and WTP for pollination by native species. Of course, higher consumer evaluations do not necessarily indicate whether tomato growers will change their approach. However, high consumer evaluations of pollination by native species may be one notable factor that encourages growers to switch from non-native to native pollinators.

This study is similar to previous studies in that it examines whether government policies aimed at ecosystem protection can be boosted through consumption (Ujiie, 2014; Yabe, Hayashi, and Nishimura, 2013). However, few studies have examined consumer evaluation with a focus on ecosystem protection. This study is the first to focus on pollination methods, including the use of non-native bumblebees, which can adversely affect the ecosystem. On the other hand, it is not a new idea to examine whether the provision of information to consumers affects their WTP, as such examination has been conducted in previous studies (Aizaki et al., 2010; Aoki et al., 2019). Nevertheless, in Japan, where bumblebees are expected to be little known to consumers, no studies have been undertaken to examine the effect of information on bumblebees on consumers' WTP. Therefore, the main contribution of this paper is to investigate the consumers' WTP for the pollination methods of tomatoes as one of the attributes of the choice experiment and to examine how the provision of information on bumblebees affects the consumers' WTP. As a result, it is expected that the labeling of pollination methods may have some effect on the protection of Japanese ecosystems.

The remainder of this paper is organized as follows. Section 2 reviews previous studies related to the above issues. Section 3 details the method. Section 4 discusses the results of the analysis. Finally, Section 5 presents the conclusions.

\section{Literature Review}

In many countries, B. terrestris is used for greenhouse tomato production; however, some countries legally prohibit its import. Almost all laws and regulations affecting the importation of nonnative bees focus on preventing the diseases and parasites associated with plants and bees and do not consider the potential adverse environmental impact associated with the bees themselves (Flanders, Wehling, and Craghead, 2003). In the United States, for example, the importation of non-Apis pollinators, including bumblebees, is regulated under the Plant Protection Act of 2000, primarily to prevent the introduction of parasites and pathogens (Vergara, 2008). Similarly, Canada also emphasizes quarantine to protect domestic ecosystems from the threats posed by non-native species.

On the other hand, policies also focus on ecological risk reduction. For example, the United Kingdom's Wildlife and Countryside Act 1981 prohibits the release of any non-native animal into the environment, including in semiconfined situations such as in commercial greenhouses (Vergara, 2008). In Mexico, due to ecological concerns, research institutions have focused on rearing native bees and have successfully pollinated tomatoes using native bees, thereby discouraging the import of bumblebees from abroad (Velthuis and Doorn, 2006).

The complications involved in commercial rearing make it difficult to develop alternative pollinators to non-native species in countries such as Japan that import non-native bumblebees (Velthuis and Doorn, 2006; Vergara, 2008). Today, it is unclear whether Japan will be able to commercially rear native species successfully and whether native species will work efficiently in regard to greenhouse tomato production. Meanwhile, many other countries are also striving to commercially rear native species with comparable efficiency to B. terrestris; however, to date, 
most countries have not been successful. In Japan, B. ignitus, a native alternative to B. terrestris, is characterized by lower rearing success rates, smaller colonies, and half the number of workers typical with $B$. terrestris. Based on this, it is estimated that tomato growers need to pay twice as much per hectare to switch from non-native to the native bumblebees; accordingly, native bumblebees are rarely welcomed by growers (Velthuis and Doorn, 2006).

On the other hand, several examples in Japan show that biodiversity-friendly farming has become more sustainable because consumer price support reduces the additional cost burden it places on farmers. Notable examples include rice production initiatives, such as Toki to Kurasu Sato (crested ibis-friendly farming), Kounotori Hagukumu Nouhou (oriental storkfriendly farming), and Sakana no Yurikago Suiden (native fish-friendly farming). Rice produced through such efforts by farmers is differentiated by the eco-label and, if supported by some consumers, can successfully be sold at higher prices than rice produced by conventional cultivation (Aoki, Akai, and Ujiie, 2017; Katada and Tanaka, 2008; Nishimura, Matsushita, and Fujie, 2012; Ujiie, 2014).

Some scholarship has already been carried out on consumer evaluations of agricultural products with such altruistic attributes in addition rice (Ujiie, 2013). Notably, previous studies dealt with consumer evaluations of tomato labeling regarding food safety and environmental considerations (Jürkenbeck, Spiller, and Meyerding, 2020; Maples et al., 2018; Meyerding, Trajer, and Lehberger, 2019; Yin et al., 2017) as well as consumer evaluations of tomatoes as functional foods (La Barbera, Amato, and Sannino, 2016; Teratanavat and Hooker, 2006; Verneau, La Barbera, and Furno, 2019). However, only a handful of studies have been conducted on consumer evaluations of pollination methods for agricultural products. Kawano (2007) estimated consumers' WTP for tomatoes grown under the legally mandated management of $B$. terrestris; however, this study considered consumer evaluations of the growers' efforts to prevent non-native species from escaping from their greenhouses and did not consider alternative pollination methods. Meanwhile, Stevens, Hoshide, and Drummond (2015) compared consumer evaluations of blueberries pollinated by commercial honeybees and native wild bees within the context of the decline in commercial honeybees resulting from Colony Collapse Disorder. The study found that US consumers are willing to pay a positive premium for blueberries pollinated by native bees. However, since it is assumed that native species are wild and not commercially distributed, the dichotomy between non-native and native pollinators is not addressed in the study. This study assumed that both non-native and native bumblebees were commercially distributed and tomato growers could select which species they used to pollinate their tomatoes.

At present, there is no standard way for Japanese consumers to know whether native or nonnative species pollinate their tomatoes. Notable related practices are evident in a few online shops that sell tomatoes with advisements that they were pollinated by native bumblebees. Meanwhile, one restaurant chain distributes illustrated booklets explaining the problems associated with B. terrestris after serving cherry tomatoes (which have not been pollinated by any bee) from contract farmers (Fujita, 2009). Generally, however, the tomatoes lined up at retail stores bear no information about how they were pollinated.

Similarly, although functional ingredient labeling of tomatoes is also uncommon, this practice can occasionally be observed in Japan. For example, compared to regular tomatoes, some grocery store chains in Japan have tomatoes that contain approximately 1.5 times the amount of lycopene, an antioxidant, or 1.5 times more GABA (gamma-aminobutyric acid), which lowers blood pressure (Kagome Co., Ltd., 2017). Such functional ingredient labeling of tomatoes offers precedents for differentiating such products from general tomatoes and may support the feasibility of labeling pollination methods.

Notably, in Japan, tomatoes labeled as grown with reduced pesticides are more commonly sold in retail stores. Aizaki et al. (2010) found that, in some prefectures in Japan, the WTP for tomatoes cultivated with half the amount of agrochemicals and chemical fertilizers was generally higher than the WTP for conventionally cultivated tomatoes. Such labeling is not uncommon for many 
Table 1. Attributes and levels of tomatoes provided in the choice experiment

\begin{tabular}{ll}
\hline Attribute & Levels \\
\hline Cultivation method & Conventional, Reduced pesticide \\
\hline Pollination method & Hormonal treatment, Non-native bumblebee, Native bumblebee \\
\hline Functional ingredients & Regular, Enriched \\
\hline Price & 78 yen, 98 yen, 118 yen, 138 yen, 158 yen \\
\hline
\end{tabular}

other agricultural products in Japan, such as rice and fresh vegetables, and such agricultural products tend to be more highly valued by consumers than those grown conventionally (Aoki et al., 2019; Matsuoka and Ujiie, 2015; Ujiie, 2014; Yabe, Hayashi, and Nishimura, 2013).

\section{Method}

\subsection{Survey Design}

The study's survey asked respondents about the price of the tomatoes they usually purchased. Two types of tomatoes are generally sold in Japanese retail stores: large tomatoes and cherry tomatoes. This study focused only on the former, which was also mentioned in the survey. However, the implications obtained in regard to the former may be applicable to the latter as well. In a choice experiment, respondents were presented with two alternatives and asked to choose their preferred alternative. The choice experiment is one of the stated preference methods for measuring consumer preference and has been applied in many previous studies (Lusk, Roosen, and Fox, 2003; Maples et al., 2018; Onozaka and McFadden, 2011). Each tomato can be distinguished by four attributes: cultivation method, pollination method, functional ingredient, and price. Table 1 shows the attributes and levels of tomatoes used in this experiment. The main concern of this study was to clarify consumer evaluations of different pollination methods. However, as mentioned above, it was expected that consumers would not be highly aware of different pollination methods.

The four attributes and their respective levels were first explained to the respondents. There were two levels of cultivation methods: "Conventional cultivation," which uses chemically synthesized pesticides and is the traditional cultivation method in Japan, and "Reduced pesticide cultivation," which uses less than half the amount of chemically synthesized pesticides. Moreover, there were three levels of pollination methods: "Hormonal treatment," "Non-native bumblebee," and "Native bumblebee." "Hormonal treatment" is a method of spraying plant growth regulators on tomato flowers such that tomato fruits can be produced without pollination. "Bumblebee" is a pollination method introduced in the 1990s; about 40\% of Japanese greenhouse tomatoes are currently pollinated by this method. "Hormonal treatment" requires a great deal of grower labor; meanwhile, the "Bumblebees" method employs bumblebees to perform the pollination work on behalf of the growers, thus helping to reduce the burden of agricultural work. "Bumblebees" were classified into two types: "native species" and "non-native species." Based on these items, two information groups were established: the first involved information on improving the quality of tomatoes through pollination by bumblebees, and the second involved information regarding the adverse effects of non-native bumblebees on ecosystems. Hereinafter, the former is referred to as Information on Quality Improvement and the latter as Information on Ecological Risk. The actual descriptions of each piece of information were as outlined below.

Information on Quality Improvement: "Bumblebee" pollination improves tomato quality.

It is an empirical fact that if the pollination method is "Bumblebee" instead of "Hormonal treatment," the following tomato quality improvement will be observed: more seeds are produced, the jelly inside the fruit is enriched, the overall shape improves, the sugar content rises, and the 
vitamin C content increases. However, whether "Bumblebees" are "non-native" or "native" does not make a difference in tomato quality.

Information on Ecological Risk: "Non-native bumblebees" have a negative impact on ecosystems.

It is an empirical fact that "Non-native bumblebees" pose the risk of harming the Japanese ecosystem, which is referred to as "ecological risk." For example, competition with "Native bumblebees" for nests and food may occur, and their biting of the flowers of wild plants can interfere with plant reproduction. Thus, using "Native bumblebees" instead of "Non-native bumblebees" for ecosystem conservation is preferred.

Respondents were divided into four groups: those who received only Information on Quality Improvement, those who received only Information on Ecological Risk, those who received Information on both, and those who received no information.

Two levels, "regular" and "enriched," were set as functional ingredients. La Barbera, Amato, and Sannino (2016) did not mention how high the lycopene content of enriched tomatoes is compared to that of regular tomatoes. As mentioned above, some retail stores in Japan sell tomatoes with a lycopene content 1.5 times higher than average. Some respondents may frequently purchase these tomatoes, which may affect the results of hypothetical experiments in this study. Therefore, the level of the attribute of the tomato was set to be so abundant that the lycopene content was not confirmed at the time of the survey. Here, it was assumed that the lycopene content of an "enriched" functional tomato was about twice as high as that of a "regular" tomato.

"Price" was set as the final attribute. The prices (excluding consumption tax) per tomato were set at $78,98,118,138$, and 158 yen. Based on the retail prices of supermarkets and department stores in the author's neighborhood as well as the prices on the Internet, the price levels did not deviate significantly from the realistic price range faced by respondents in their daily lives.

In the choice experiments in this study, a full factorial design was generated, which consisted of all possible combinations of attribute levels. Based on these product profiles, two product profiles were randomly paired based on the mix-and-match method, for which the first alternatives were assigned from a set of all product profiles and the second alternatives were assigned from another set with the same contents without replacement, to create choice sets. No useless set was included in the $60(=2 \times 3 \times 2 \times 5)$ choice sets created. According to the choice experiment literature (e.g., Louviere, Hensher, and Swait, 2000), this number was too large for a complete answer by the respondents, so the study divided the 60 choice sets into 6 blocks and asked each respondent to answer 10 questions during the choice experiment. These choice sets were created using R 3.5.3 (R Core Team, 2019) with the "support.CEs" package (Aizaki, 2012). The respondents were presented with two types of tomatoes with different levels of each attribute and asked which one they would like to purchase. There was also an opt-out alternative, "I would not purchase either tomato." Figure 1 shows an example of the choice set presented to the respondents. Before conducting the choice experiment, "cheap talk script" (see Appendix A) was described to mitigate hypothetical bias in the choice experiment (Aoki, Akai, and Ujiie, 2017; Liu et al., 2019).

\subsection{Prior Knowledge and Attitudes}

Following the questions about the choice experiment, respondents were first asked whether they knew about the pollination methods for tomatoes and their functional ingredients. More specifically, the study asked respondents about their previous knowledge regarding pollination methods, knowledge of hormonal treatment in greenhouse tomato production, and the use of bumblebees as pollinators. Meanwhile, the study also asked respondents about their knowledge regarding the function of lycopene in tomatoes. Because, as mentioned above, some Japanese retailers sell tomatoes labeled as having an enriched lycopene content, but the labeling of pollination methods is 
Suppose the following two types of tomatoes are lined up in the store. Which one would you like to purchase?

\begin{tabular}{lcc}
\hline & Tomato A & Tomato B \\
\hline Cultivation method & Reduced pesticide & Conventional \\
Pollination method & Non-native bumblebee & Native bumblebee \\
Functional ingredients & Regular & Enriched \\
Price & 98 yen & 118 yen \\
\hline
\end{tabular}

I would purchase Tomato A.

I would purchase Tomato B.

I would not purchase either type of tomato.

Figure 1. An example of the choice set.

rare, the study expected respondents to understand the function of lycopene but to know little about pollination.

The evaluation of tomato attributes that may affect ecosystems or consumer health is not explained solely by socio-demographic variables such as age and household income but also by consumer attitudes toward environmental issues. Therefore, this study explored ways to understand consumers' purchasing behavior by characterizing consumers with unobservable latent variables. More specifically, the study attempted to explore the latent variables characterizing its respondents by gauging not only their attitudes to issues regarding ecosystems and the global environment but also their lifestyles and ways of thinking about organic agricultural products. Respondents were asked questions about eleven items, as shown in Table 3, to understand such consumer attitudes. They were asked to answer each question using a five-point Likert scale from "strongly agree" $=5$ to "do not agree at all" $=1$, centering on "neither." A factor analysis of these responses was conducted using R 3.6.2 with the "psych" package (Revelle, 2019).

\subsection{Econometric Model}

This study employed random parameter logit models to analyze the answers obtained in the choice experiment (Train, 2009). The advantages of the random parameter logit model include the fact that it is not subject to the assumption of the independence of irrelevant alternatives and its incorporation of the heterogeneity of consumer preferences. Previous studies dealing with choice experiments on food labeling have used such models to take into account the heterogeneity of respondents in regard to consumer preferences (Aizaki et al., 2010; Aoki et al., 2019; Lusk, Roosen, and Fox, 2003).

In the random parameter logit model, when the individual $n$ faces a choice among $J$ alternatives, the utility of the individual $n$ choosing alternative $j$ in choice situation $t$ can be specified as

$$
U_{n j t}=\beta_{n}^{\prime} x_{n j t}+\varepsilon_{n j t},
$$

where $x_{n j t}$ is a vector of attributes of the alternative $j, \beta_{n}$ is a vector of coefficients of these attributes for an individual $n$ representing $n$ 's tastes, and $\varepsilon_{n j t}$ is the stochastic component. The conditional probability of an alternative $j$ for an individual $n$ in choice situation $t$ is expressed as

$$
L_{n i}\left(\beta_{n}\right)=\frac{e^{\beta_{n}^{\prime} x_{n i t}}}{\sum_{j=1}^{J} e^{\beta_{n} x_{n i t}}} .
$$


Consider a sequence of alternatives, one for each time period $\mathbf{i}=\left\{i_{1}, \ldots, i_{T}\right\}$. Conditional on $\beta$, the probability that an individual makes this sequence of choices is expressed as

$$
L_{n \mathbf{i}}\left(\beta_{n}\right)=\prod_{t=1}^{T} \frac{e^{\beta_{n}^{\prime} x_{n i t} t}}{\sum_{j=1}^{J} e^{\beta_{n}^{\prime} x_{n j t}}} .
$$

The unconditional probability is the integral of this product over all values of $\beta$

$$
P_{n \mathbf{i}}=\int L_{n \mathbf{i}}(\beta) f(\beta \mid \theta) d \beta .
$$

The probability is simulated by taking draws of $\beta$ from the population distribution, $f(\beta \mid \theta)$ where $\theta$ signifies the parameters of this distribution. The parameters of the model were estimated using the maximum simulated likelihood estimation procedures. In most applications, it is common to make an assumption regarding the distribution of each of the random parameters. This study assumed that the price coefficient was fixed across individuals, which facilitated the estimation and calculation of WTP (Revelt and Train, 1998); meanwhile, the coefficients of all attributes of the choice experiment other than price were assumed to be random terms and specified as normally distributed (Aoki, Akai, and Ujiie, 2017; Carlsson, Frykblom, and Liljenstolpe, 2003; Lusk, Roosen, and Fox, 2003).

In the following analysis, each attribute except for the price was treated as a dummy variable. That is, HALVE was a dummy variable for the cultivation method; it was set at 1 for reduced pesticides and 0 for conventional. Regarding the pollination method, tomatoes pollinated using non-native bumblebees were used as the reference level. Therefore, HORMONE was also a dummy variable; it was set at 1 if hormonal treatment was used as the pollination method and 0 otherwise. Similarly, NATIVE was a dummy variable related to the pollination method; it was set at 1 if native bumblebees were used and 0 otherwise. ENRICHED was another dummy variable; it was set at 1 when the functional ingredients were enriched (i.e., if the lycopene content was about twice as high as that of regular tomatoes) and 0 in regular cases.

All random parameters logit models were estimated in R 4.0.2 with the "gmnl" package (Sarrias and Daziano, 2017), which helped estimate multinomial logit models with random parameters, using the BFGS procedure with 1,000 Halton draws.

The mean WTP estimate for each attribute was calculated by dividing the mean parameter of non-price attributes by the coefficient of the price and multiplying by -1 . In addition, the $95 \%$ confidence intervals for the WTP were estimated using the parametric bootstrapping procedure of Krinsky and Robb (1986). For comparisons between WTPs of the four groups according to the information the respondents provided, a complete combinatorial test (Poe, Giraud, and Loomis, 2005) was applied, where the null hypothesis was equal for both WTPs and the alternative hypothesis was that the WTP with a higher estimate was higher than another WTP. These tests were performed using R 4.0.2 with the "mded" package (Aizaki, 2015).

\subsection{Data Collection}

The data employed in this study were collected via an online questionnaire survey. An Internet research company, Macromill, Inc., which designs and conducts online surveys according to the request of the survey client and pays individuals who have registered as survey respondent candidates to serve as respondents, was commissioned to conduct the survey. The survey was conducted in March 2019; potential participants were required to live in Japan and be over 18 years of age. Prior to the survey, a screening survey asked candidates, "Do you usually purchase fresh tomatoes (here, large tomatoes, not cherry tomatoes) at supermarkets, department stores, farmers' markets, or Marche?," to ensure that respondents regularly purchased fresh tomatoes. This screening was conducted on a subset of registered members and offered four potential replies: 
"frequent," "sometimes," "rarely," and "none at all." In response to this question, respondents who chose "frequent" or "sometimes" were considered tomato consumers who were meaningful for this study and were included in the survey. Ultimately, responses were obtained from 1,250 consumers.

\section{Results and Discussion}

\subsection{Sample Description}

Table 2 shows the socio-demographic characteristics of the survey respondents, along with the Japanese population ratio and their previous knowledge of the pollination methods and functional ingredients of tomatoes.

As noted above, the survey employed 1,250 Japanese respondents over the age of 18 years. More than half of the respondents were female; the gender ratio did not significantly differ from that of Japan as a whole. Meanwhile, the proportion of respondents in the 30s to 50s and over 60 age groups were respectively relatively higher and lower than those of the general Japanese population. Therefore, the age distribution of the sample did not perfectly represent the Japanese population, perhaps because an online survey was used and seniors tend to use the Internet less frequently and are thus less likely to be the subjects of online surveys. The average and median ages of the respondents were 47.1 and 46.0, respectively; meanwhile, the average age of the Japanese population was not available, and the median age was 48.6 (CIA World Factbook 2020 est.). Therefore, the respondents were slightly younger than the median of the Japanese population. The survey included responses from residents of all forty-seven prefectures in Japan and the distribution of respondents' regions of residence approximated that of Japan. Finally, the sample's household income distribution also approximated that of the Japanese population, although the proportion of high-income earners tended to be large, perhaps again because it was an online survey and the Internet is a significant expense. Overall, the socio-demographic characteristics of the sample were close to representative of the Japanese population.

\subsubsection{The Price of Tomatoes that Respondents Usually Purchased}

Respondents were asked about the price of the tomatoes they usually purchased before conducting the choice experiment. In general, Japanese supermarkets and department stores sell not only individual tomatoes but also several tomatoes packed in plastic containers or bags. Respondents were asked if they usually purchased tomatoes individually or in a pack. If their daily purchase habits differed, then they were asked which kind of tomato they purchased most frequently. Ultimately, 660 (52.8\%) respondents answered that they purchased individual tomatoes, and 590 (47.2\%) answered that they purchased tomatoes sold in packs. Subsequently, they were asked about the price of these tomatoes without consumption tax. The average price per tomato for those who usually purchased tomatoes sold individually was 129.6 yen, and the median was 100.0 yen. However, the average price of one pack of tomatoes that respondents usually purchased was 322.4 yen, and the median was 300.0 yen. Each pack contained an average of 4.2 tomatoes and a median of 4.0 tomatoes. Hence, the average price per tomato sold in a pack was 83.3 yen, and the median was 79.6 yen. Although the price per tomato sold in packs was lower than the price of tomatoes sold individually, the price levels set in the choice experiment in this study remained generally reasonable.

\subsubsection{Previous Knowledge of Pollination Methods and Functional Ingredients}

Consumers in Japan are rarely advised of tomato pollination methods when purchasing tomatoes and are, accordingly, seldom conscious of pollination methods. Thus, respondents are unlikely to know about the use of hormonal treatments or bumblebees in greenhouse tomato production. Along these lines, respondents were asked whether they knew the following before the survey: 
Table 2. Sociodemographic characteristics of respondents relative to the Japanese population

\begin{tabular}{|c|c|c|c|}
\hline Characteristics specification & Respondents & $\%$ of Respondents & $\%$ of Japanese population* \\
\hline \multicolumn{4}{|l|}{ Gender } \\
\hline Female & 715 & 57.2 & 51.3 \\
\hline Male & 535 & 42.8 & 48.7 \\
\hline \multicolumn{4}{|l|}{ Age } \\
\hline $18-19$ years & 13 & 1.0 & 1.9 \\
\hline 20-29 years & 127 & 10.2 & 9.7 \\
\hline $30-39$ years & 285 & 22.8 & 12.3 \\
\hline $40-49$ years & 302 & 24.2 & 14.5 \\
\hline $50-59$ years & 262 & 21.0 & 12.2 \\
\hline 60 years or older & 261 & 20.9 & 33.0 \\
\hline \multicolumn{4}{|l|}{ Regions of residence in Japan } \\
\hline Hokkaido & 63 & 5.0 & 4.2 \\
\hline Tohoku & 78 & 6.2 & 7.1 \\
\hline Kanto & 441 & 35.3 & 33.8 \\
\hline Chubu & 220 & 17.6 & 18.3 \\
\hline Kinki & 244 & 19.5 & 16.3 \\
\hline Chugoku & 64 & 5.1 & 5.9 \\
\hline Shikoku & 30 & 2.4 & 3.0 \\
\hline Kyushu & 110 & 8.8 & 11.4 \\
\hline \multicolumn{4}{|l|}{ Household income (per year) } \\
\hline Less than 2 million yen & 55 & 4.4 & 18.0 \\
\hline 2-4 million yen & 234 & 18.7 & 30.4 \\
\hline 4-6 million yen & 288 & 23.0 & 11.6 (4-5 million yen) \\
\hline 6-8 million yen & 159 & 12.7 & 14.7 (5-7 million yen) \\
\hline 8-10 million yen & 104 & 8.3 & 10.8 (7-10 million yen) \\
\hline 10-12 million yen & 60 & 4.8 & 4.9 (10-15 million yen) \\
\hline 12-15 million yen & 28 & 2.2 & - \\
\hline 15-20 million yen & 21 & 1.7 & 1.0 \\
\hline 20 million yen or more & 11 & 0.9 & 0.7 \\
\hline Do not know & 117 & 9.4 & \\
\hline No answer & 173 & 13.8 & \\
\hline
\end{tabular}

Knowledge before the survey on pollination methods

In some cases, greenhouse tomatoes are treated with hormones.

\begin{tabular}{lcc} 
Known before the survey & 121 & 9.7 \\
\hline I did not know & 1,129 & 90.3
\end{tabular}


Table 2. (Continued)

\begin{tabular}{|c|c|c|c|}
\hline Characteristics specification & Respondents & $\%$ of Respondents & $\%$ of Japanese population* \\
\hline \multicolumn{4}{|c|}{$\begin{array}{l}\text { In some cases, bumblebees } \\
\text { are used to pollinate greenhouse } \\
\text { tomatoes. }\end{array}$} \\
\hline Known before the survey & 192 & 15.4 & \\
\hline I did not know & 1,058 & 84.6 & \\
\hline \multicolumn{4}{|l|}{$\begin{array}{l}\text { Knowledge before the survey } \\
\text { on lycopene function }\end{array}$} \\
\hline \multicolumn{4}{|c|}{$\begin{array}{l}\text { Lycopene contained in tomatoes } \\
\text { helps prevent lifestyle-related } \\
\text { diseases. }\end{array}$} \\
\hline Known before the survey & 1,069 & 85.5 & \\
\hline I did not know & 181 & 14.5 & \\
\hline
\end{tabular}

Sources: *Japanese Census Data, 2015, except for household income (Housing and land statistics survey in Japan, 2018).

"In some cases, greenhouse tomatoes are treated with hormones" and "In some cases, bumblebees are used to pollinate greenhouse tomatoes." As shown in Table 2, only $9.7 \%$ of respondents knew the former, while $15.4 \%$ knew the latter. These results indicated that most respondents did not know anything about pollination methods for tomatoes. To understand the respondents' knowledge regarding the functional ingredients contained in tomatoes, they were asked if they knew the following: "Lycopene contained in tomatoes helps to prevent lifestyle-related diseases." As shown in Table 2, in contrast to the responses regarding pollination methods, $85.5 \%$ of respondents knew the function of lycopene in tomatoes.

\subsection{Factor Analysis}

Table 3 presents factor loadings from the factor analysis obtained after a Promax rotation of responses to the 11 questions asked in this survey. Based on the suggestion from a parallel analysis, in the factor analysis, the number of factors was set to four. Cronbach's alpha was 0.76 for the answers to these questions.

Factor 1 (environmental stewardship) indicates that humans should take responsibility for the current ecosystem and rethink approaches to a convenient way of life. Factor 2 (social involvement) is an indication of willingness to influence surrounding people as members of the community to which the user belongs. Factor 3 (seasonal sensitivity) leads to a lifestyle that is sensitive to seasonal changes and implies healthy behaviors. Factor 4 (organic orientation) indicates the desire to purchase organic produce. In the following analysis, respondent scores for each of the four factors were used as characterizing variables.

\subsection{Model Estimation}

\subsubsection{Random Parameter Logit Models}

Table 4 shows the estimation results of the random parameter logit models. In the survey conducted in this study, 17 respondents chose "I would not purchase either type of tomato" for all questions in the choice experiment; these were regarded as "resistance responses" and were excluded from the analysis. Thus, 1,233 respondents were considered in the final analysis. Respondents were divided into four groups according to the information they provided. Approximately 300 respondents were in each group.

The coefficients of the alternative-specific constant for the opt-out option, ASC (no-purchase), were negative and statistically significant at the $1 \%$ level. This result means that respondents tend 
Table 3. Results of factor analysis

\begin{tabular}{|c|c|c|c|c|}
\hline Items & $\begin{array}{l}\text { Factor 1: } \\
\text { Environmental } \\
\text { Stewardship }\end{array}$ & $\begin{array}{l}\text { Factor 2: } \\
\text { Social } \\
\text { Involvement }\end{array}$ & $\begin{array}{l}\text { Factor 3: } \\
\text { Seasonal } \\
\text { Sensitivity }\end{array}$ & $\begin{array}{l}\text { Factor 4: } \\
\text { Organic } \\
\text { Orientation }\end{array}$ \\
\hline $\begin{array}{l}\text { Humans have a responsibility to protect the } \\
\text { ecosystems on Earth. }\end{array}$ & 0.74 & -0.02 & -0.04 & 0.03 \\
\hline $\begin{array}{l}\text { Endangered species should be protected from } \\
\text { extinction. }\end{array}$ & 0.61 & -0.01 & -0.04 & 0.07 \\
\hline $\begin{array}{l}\text { Solving global environmental problems requires not } \\
\text { only technological innovation but also a review of } \\
\text { our convenient lifestyles. }\end{array}$ & 0.55 & 0.08 & 0.00 & 0.01 \\
\hline $\begin{array}{l}\text { I sometimes pay attention to people who do not } \\
\text { sort garbage. }\end{array}$ & -0.04 & 0.78 & -0.15 & 0.15 \\
\hline $\begin{array}{l}\text { I sometimes persuade my family and friends not to } \\
\text { buy products that have a negative impact on the } \\
\text { global environment. }\end{array}$ & 0.05 & 0.69 & -0.03 & -0.09 \\
\hline I want to use a community garden. & 0.00 & 0.39 & 0.16 & -0.06 \\
\hline $\begin{array}{l}\text { When I shop, I care about the season of vegetables } \\
\text { and fruits. }\end{array}$ & -0.09 & -0.04 & 0.73 & 0.10 \\
\hline $\begin{array}{l}\text { I feel the seasonal changes by looking at the } \\
\text { flowers. }\end{array}$ & 0.30 & -0.09 & 0.52 & -0.15 \\
\hline I try to keep my diet as healthy as possible. & -0.08 & 0.07 & 0.49 & 0.13 \\
\hline $\begin{array}{l}\text { I do not buy foods made with genetically modified } \\
\text { crops. }\end{array}$ & 0.02 & -0.07 & 0.04 & 0.63 \\
\hline If possible, I want to eat only organic produce. & 0.10 & 0.07 & 0.08 & 0.50 \\
\hline \% Variance Explained & 0.12 & 0.11 & 0.10 & 0.07 \\
\hline Cumulative $\%$ Variance & 0.12 & 0.24 & 0.34 & 0.41 \\
\hline
\end{tabular}

Factor loadings greater than 0.30 are highlighted in bold.

to prefer one of the proposed tomatoes. In addition, the price coefficients were negative (as expected) and statistically different from 0 at the $1 \%$ level. Therefore, price increases negatively affected respondents' utility.

The estimates of HALVE, NATIVE, and ENRICHED were positive and statistically significant at the $5 \%$ level in all models. These results indicate that the respondents preferred tomatoes cultivated with fewer pesticides and pollinated by native bumblebees. Moreover, respondents also preferred tomatoes with more enriched functional ingredients over regular tomatoes. Meanwhile, HORMONE proved negative and statistically significant at the $1 \%$ level in all models, indicating that respondents did not prefer tomatoes treated with hormones to those pollinated by non-native bumblebees. In addition, comparing the negative values of HORMONE and price coefficient to the negative values of the ASC coefficient, respondents' utility derived from purchasing hormone-treated tomatoes with relatively high prices may be lower than their utility derived from choosing none of the proposed tomatoes. These results were common across all four groups, depending on the information provision. Therefore, it was found that respondents prefer tomatoes labeled with reduced pesticides, pollination by bumblebees (particularly native species), and rich in functional ingredients, whether or not information on bumblebees is provided.

Standard deviations were also estimated for random parameters, among which some standard deviations were statistically different from 0 at the $5 \%$ level, suggesting heterogeneity in respondent preferences. 
Table 4. Estimates of parameters for random parameters logit models

\begin{tabular}{|c|c|c|c|c|c|c|c|c|}
\hline \multirow[b]{2}{*}{ Variables } & \multicolumn{2}{|c|}{ No Information } & \multicolumn{2}{|c|}{$\begin{array}{l}\text { Only Information on Quality } \\
\text { Improvement }\end{array}$} & \multicolumn{2}{|c|}{$\begin{array}{l}\text { Only Information } \\
\text { on Ecological Risk }\end{array}$} & \multicolumn{2}{|c|}{ Information on Both } \\
\hline & Estimate & Standard Errors & Estimate & Standard Errors & Estimate & Standard Errors & Estimate & Standard Errors \\
\hline ASC (no-purchase) & $-3.867^{\star \star \star}$ & 0.313 & $-3.614^{\star \star \star}$ & 0.163 & $-3.876^{\star \star \star}$ & 0.258 & $-3.307^{\star \star \star}$ & 0.317 \\
\hline Price & $-0.027^{\star \star \star}$ & 0.003 & $-0.022^{\star \star \star}$ & 0.001 & $-0.026^{\star \star \star}$ & 0.002 & $-0.020^{\star \star \star}$ & 0.003 \\
\hline \multicolumn{9}{|l|}{$\begin{array}{l}\text { Mean of random } \\
\text { parameters }\end{array}$} \\
\hline HALVE & $0.500^{\star \star \star}$ & 0.075 & $0.476^{\star \star \star}$ & 0.045 & $0.458^{\star \star \star}$ & 0.055 & $0.482^{\star \star \star}$ & 0.076 \\
\hline HORMONE & $-0.464^{\star \star \star}$ & 0.088 & $-0.372^{\star \star \star}$ & 0.061 & $-0.247^{\star \star \star}$ & 0.069 & $-0.276^{\star \star \star}$ & 0.080 \\
\hline NATIVE & $0.269^{\star \star \star}$ & 0.073 & $0.319^{\star \star *}$ & 0.059 & $0.529^{\star \star \star}$ & 0.079 & $0.623^{\star \star \star}$ & 0.108 \\
\hline ENRICHED & $0.227^{\star \star \star}$ & 0.054 & $0.164^{\star \star \star}$ & 0.043 & $0.119^{\star \star}$ & 0.049 & $0.134^{\star \star}$ & 0.053 \\
\hline \multicolumn{9}{|c|}{$\begin{array}{l}\text { Standard deviation } \\
\text { of random parameters }\end{array}$} \\
\hline HALVE & 0.423 & 0.441 & 0.194 & 0.460 & $0.859^{\star \star}$ & 0.343 & $0.791^{*}$ & 0.443 \\
\hline HORMONE & 0.269 & 0.392 & 0.044 & 0.326 & 0.057 & 0.258 & 0.211 & 0.406 \\
\hline NATIVE & 0.058 & 0.217 & 0.029 & 0.194 & 0.067 & 0.288 & 0.029 & 0.252 \\
\hline ENRICHED & $1.013^{\star \star}$ & 0.451 & 0.171 & 0.441 & 0.302 & 0.410 & 0.661 & 0.493 \\
\hline No. of observations & 3,090 & & 3,100 & & 3,180 & & 2,960 & \\
\hline No. of respondents & 309 & & 310 & & 318 & & 296 & \\
\hline $\begin{array}{l}\text { Log-likelihood at } \\
\text { convergence }\end{array}$ & $-2,618$ & & $-2,500$ & & $-2,675$ & & $-2,483$ & \\
\hline McFadden's $R^{2}$ & 0.229 & & 0.266 & & 0.235 & & 0.236 & \\
\hline AIC & 5,255 & & 5,021 & & 5,371 & & 4,986 & \\
\hline $\mathrm{BIC}$ & 5,316 & & 5,081 & & 5,431 & & 5,046 & \\
\hline
\end{tabular}

${ }^{*},{ }^{* *}$, and ${ }^{* * *}$ indicate significance at the $10 \%, 5 \%$, and $1 \%$ levels, respectively. 


\subsubsection{Random Parameter Logit Models with Interaction Terms}

Table 5 shows the estimation results of the random parameter logit models with the interaction terms. The interaction terms of the model included age and household income as the available socio-demographic variables, the four variables obtained from the above factor analysis, and previous knowledge on the pollination methods and functional ingredients of tomatoes. Age was a variable of the respondents' actual age, and household income was a variable represented by the nine-step ordinal scale shown in Table 2. The three variables related to previous knowledge were dummy variables and were set at 1 if the respondent had the according knowledge and 0 otherwise.

Note that respondents were not asked about household income; data were instead collected from the company that commissioned the survey because it already had the data of the respondents on hand; missing values exist because the company did not mandate the disclosure of this information. As shown in Table 2, 117 respondents chose "Do not know," and 173 respondents did not answer. Respondents with no household income data were excluded from the following analysis. As a result of the reduced number of respondents, the results of 949 respondents were used to estimate the models. Approximately 240 respondents were in each group. Compared with the model without interaction terms, the model with interaction terms improved McFadden's $\mathrm{R}^{2}$, which is one of the measures of model fit, for each of the four models.

In each of these models, the coefficients of ASC (no-purchase) and Price were negative, as in Table 4. Most of the other random parameters were not significant, and the preferences of respondents were primarily expressed by the estimates of the interaction terms. Among the random parameters, all interaction terms with tomato attributes were significant. However, no interaction term regarding information provision proved significant across all groups, and the effect of information provision was often ambiguous, making between-group comparisons conservative.

Regarding environmental stewardship, interactions with NATIVE were positive if some information on bumblebees was provided to respondents. This means that by providing information on bumblebees (improvement in tomato quality or ecological risk), respondents who believed that humans should take responsibility for the current ecosystem preferred tomatoes pollinated by native bumblebees over non-native ones. While it makes sense that the provision of information on the ecological risks posed by non-native species makes respondents who feel responsible for protecting the ecosystem prefer native species, a similar effect was confirmed for information on the ways in which bumblebees improve tomato quality.

In addition, regarding participants' previous knowledge of bumblebees, it is helpful to note that the interaction with HORMONE was negative when information about bumblebees was provided to respondents. This means that by providing information on bumblebees (i.e., their improvement of tomato quality or ecological risk), respondents who previously knew about the pollination of tomatoes by bumblebees preferred tomatoes pollinated by non-native bumblebees over hormone-treated ones. When non-native bumblebees were introduced into Japan, bumblebee pollination was considered an environmentally friendly agricultural practice because tomato growers would no longer need to use plant growth regulators, which are a type of pesticide, and chemical use was thus restricted so that worker bee activity was not adversely affected (Ono and Wada, 1996; Velthuis and Doorn, 2006). Currently, due to the potential ecological risks posed by non-native bumblebees, their use as pollinators cannot be declared an environmentally friendly agricultural practice. However, respondents with enhanced knowledge of bumblebees still demonstrated a negative impression of the use of plant growth regulators. Notably, Gosterit and Gurel (2018) acknowledge that commercially reared bumblebees may disturb local ecosystems but emphasize that their use as pollinators also contributes to the necessity of Good Agricultural Practices (GAP), such as environmental sustainability, economic viability, social acceptability, and food safety and quality, when compared to plant growth regulators. 
Table 5. Estimates of parameters for random parameters logit models with interaction terms

\begin{tabular}{|c|c|c|c|c|c|c|c|c|}
\hline \multirow[b]{2}{*}{ Variables } & \multicolumn{2}{|c|}{ No Information } & \multicolumn{2}{|c|}{$\begin{array}{l}\text { Only Information on Quality } \\
\text { Improvement }\end{array}$} & \multicolumn{2}{|c|}{$\begin{array}{l}\text { Only Information on } \\
\text { Ecological Risk }\end{array}$} & \multicolumn{2}{|c|}{ Information on Both } \\
\hline & Estimate & Standard Errors & Estimate & Standard Errors & Estimate & Standard Errors & Estimate & Standard Errors \\
\hline ASC (no-purchase) & $-4.493^{\star \star \star}$ & 0.346 & $-3.871^{\star \star \star}$ & 0.197 & $-3.888^{\star \star \star}$ & 0.206 & $-3.797^{\star \star \star}$ & 0.449 \\
\hline Price & $-0.033^{\star \star \star}$ & 0.003 & $-0.022^{\star \star \star}$ & 0.002 & $-0.025^{\star \star \star}$ & 0.002 & $-0.024^{\star \star \star}$ & 0.004 \\
\hline \multicolumn{9}{|l|}{ Mean of random parameters } \\
\hline HALVE & $0.630^{*}$ & 0.339 & 0.261 & 0.218 & 0.147 & 0.235 & 0.046 & 0.324 \\
\hline HORMONE & $-1.634^{\star \star \star}$ & 0.457 & 0.011 & 0.295 & 0.165 & 0.313 & -0.120 & 0.433 \\
\hline NATIVE & 0.173 & 0.479 & 0.331 & 0.309 & -0.073 & 0.340 & 0.520 & 0.465 \\
\hline ENRICHED & $1.641^{\star \star \star}$ & 0.377 & 0.090 & 0.218 & 0.124 & 0.240 & -0.039 & 0.335 \\
\hline \multicolumn{9}{|l|}{ Interaction terms } \\
\hline HALVE $\times$ Age & $-0.011^{\star \star}$ & 0.005 & 0.005 & 0.003 & 0.003 & 0.004 & 0.007 & 0.005 \\
\hline HALVE $\times$ Household Income & 0.053 & 0.041 & 0.008 & 0.027 & $0.086^{\star \star *}$ & 0.029 & 0.032 & 0.038 \\
\hline HALVE $\times$ Environmental Stewardship & $0.173^{\star *}$ & 0.069 & $0.076^{*}$ & 0.044 & 0.071 & 0.044 & $0.117^{\star}$ & 0.060 \\
\hline HALVE $\times$ Social Involvement & 0.006 & 0.065 & -0.057 & 0.043 & -0.018 & 0.043 & 0.028 & 0.065 \\
\hline HALVE $\times$ Seasonal Sensitivity & 0.065 & 0.063 & $0.116^{\star \star \star}$ & 0.043 & -0.044 & 0.047 & 0.039 & 0.055 \\
\hline HALVE $\times$ Organic Orientation & $0.088^{*}$ & 0.052 & 0.009 & 0.035 & $0.070^{*}$ & 0.037 & 0.012 & 0.052 \\
\hline HALVE $\times$ Previous Knowledge on Hormone & -0.010 & 0.242 & -0.086 & 0.165 & -0.228 & 0.175 & -0.171 & 0.245 \\
\hline HALVE $\times$ Previous Knowledge on Bumblebee & 0.012 & 0.185 & 0.023 & 0.146 & -0.196 & 0.157 & -0.062 & 0.201 \\
\hline HALVE $\times$ Previous Knowledge on Lycopene & $0.430^{\star \star}$ & 0.193 & -0.080 & 0.129 & -0.140 & 0.144 & 0.132 & 0.200 \\
\hline HORMONE $\times$ Age & $0.010^{\star}$ & 0.006 & -0.004 & 0.005 & -0.001 & 0.005 & -0.002 & 0.006 \\
\hline HORMONE $\times$ Household Income & 0.039 & 0.053 & -0.027 & 0.037 & -0.064 & 0.039 & 0.044 & 0.050 \\
\hline HORMONE $\times$ Environmental Stewardship & 0.019 & 0.085 & $-0.106^{\star}$ & 0.060 & 0.021 & 0.058 & 0.018 & 0.075 \\
\hline HORMONE $\times$ Social Involvement & $0.172^{\star \star}$ & 0.084 & 0.056 & 0.058 & $-0.180^{\star \star \star}$ & 0.058 & -0.020 & 0.085 \\
\hline
\end{tabular}


Table 5. (Continued)

\begin{tabular}{|c|c|c|c|c|c|c|c|c|}
\hline \multirow[b]{2}{*}{ Variables } & \multicolumn{2}{|c|}{ No Information } & \multicolumn{2}{|c|}{$\begin{array}{c}\text { Only Information on Quality } \\
\text { Improvement }\end{array}$} & \multicolumn{2}{|c|}{$\begin{array}{l}\text { Only Information on } \\
\text { Ecological Risk }\end{array}$} & \multicolumn{2}{|c|}{ Information on Both } \\
\hline & Estimate & Standard Errors & Estimate & Standard Errors & Estimate & Standard Errors & Estimate & Standard Errors \\
\hline HORMONE $\times$ Seasonal Sensitivity & $-0.211^{\star \star \star}$ & 0.081 & -0.010 & 0.057 & 0.052 & 0.062 & $-0.146^{\star}$ & 0.076 \\
\hline HORMONE $\times$ Organic Orientation & -0.092 & 0.068 & $0.088^{*}$ & 0.047 & 0.041 & 0.049 & -0.089 & 0.068 \\
\hline HORMONE $\times$ Previous Knowledge on Hormone & -0.029 & 0.310 & $0.410^{\star}$ & 0.227 & -0.095 & 0.227 & -0.422 & 0.333 \\
\hline HORMONE $\times$ Previous Knowledge on Bumblebee & -0.052 & 0.240 & $-0.636^{\star \star \star}$ & 0.200 & $-0.475^{\star \star}$ & 0.207 & $-0.803^{\star \star \star}$ & 0.285 \\
\hline HORMONE $\times$ Previous Knowledge on Lycopene & $0.462^{*}$ & 0.237 & -0.034 & 0.174 & -0.059 & 0.190 & -0.008 & 0.262 \\
\hline NATIVE $\times$ Age & 0.001 & 0.007 & 0.003 & 0.005 & $0.009^{\star}$ & 0.005 & 0.007 & 0.007 \\
\hline NATIVE $\times$ Household Income & 0.020 & 0.059 & 0.038 & 0.039 & -0.021 & 0.042 & -0.018 & 0.055 \\
\hline NATIVE $\times$ Environmental Stewardship & 0.077 & 0.098 & $0.145^{\star \star}$ & 0.064 & $0.132^{\star \star}$ & 0.063 & $0.144^{\star}$ & 0.084 \\
\hline NATIVE $\times$ Social Involvement & 0.052 & 0.094 & 0.025 & 0.062 & $-0.192^{\star \star \star}$ & 0.062 & 0.009 & 0.094 \\
\hline NATIVE $\times$ Seasonal Sensitivity & 0.017 & 0.091 & 0.013 & 0.061 & $0.164^{\star \star}$ & 0.067 & $-0.159^{\star}$ & 0.082 \\
\hline NATIVE $\times$ Organic Orientation & 0.075 & 0.077 & -0.004 & 0.049 & $0.088^{\star}$ & 0.053 & 0.077 & 0.077 \\
\hline NATIVE $\times$ Previous Knowledge on Hormone & -0.125 & 0.352 & 0.011 & 0.236 & -0.301 & 0.244 & $-0.650^{\star}$ & 0.355 \\
\hline NATIVE $\times$ Previous Knowledge on Bumblebee & 0.241 & 0.270 & 0.280 & 0.205 & -0.143 & 0.219 & $0.857^{\star \star \star}$ & 0.321 \\
\hline NATIVE $\times$ Previous Knowledge on Lycopene & -0.011 & 0.267 & $-0.373^{\star \star}$ & 0.184 & 0.228 & 0.212 & -0.088 & 0.283 \\
\hline ENRICHED $\times$ Age & $-0.028^{\star \star \star}$ & 0.006 & $-0.009^{\star * \star}$ & 0.003 & $-0.007^{\star \star}$ & 0.004 & -0.001 & 0.005 \\
\hline ENRICHED $\times$ Household Income & -0.012 & 0.044 & $0.071^{\star \star}$ & 0.028 & $0.063^{\star *}$ & 0.029 & 0.055 & 0.041 \\
\hline ENRICHED $\times$ Environmental Stewardship & 0.042 & 0.072 & $0.076^{*}$ & 0.045 & $0.109^{\star \star}$ & 0.044 & -0.033 & 0.059 \\
\hline ENRICHED $\times$ Social Involvement & 0.083 & 0.069 & 0.006 & 0.043 & -0.042 & 0.043 & 0.011 & 0.067 \\
\hline ENRICHED $\times$ Seasonal Sensitivity & 0.085 & 0.068 & 0.015 & 0.043 & 0.002 & 0.048 & 0.020 & 0.057 \\
\hline ENRICHED $\times$ Organic Orientation & $-0.161^{\star \star \star}$ & 0.057 & -0.018 & 0.034 & -0.023 & 0.038 & -0.018 & 0.055 \\
\hline ENRICHED $\times$ Previous Knowledge on Hormone & 0.031 & 0.262 & -0.108 & 0.164 & 0.029 & 0.172 & 0.110 & 0.253 \\
\hline ENRICHED $\times$ Previous Knowledge on Bumblebee & -0.053 & 0.200 & 0.126 & 0.146 & -0.038 & 0.157 & -0.250 & 0.214 \\
\hline
\end{tabular}


Table 5. (Continued)

\begin{tabular}{|c|c|c|c|c|c|c|c|c|}
\hline \multirow[b]{2}{*}{ Variables } & \multicolumn{2}{|c|}{ No Information } & \multicolumn{2}{|c|}{$\begin{array}{l}\text { Only Information on Quality } \\
\text { Improvement }\end{array}$} & \multicolumn{2}{|c|}{$\begin{array}{l}\text { Only Information on } \\
\text { Ecological Risk }\end{array}$} & \multicolumn{2}{|c|}{ Information on Both } \\
\hline & Estimate & Standard Errors & Estimate & Standard Errors & Estimate & Standard Errors & Estimate & Standard Errors \\
\hline ENRICHED $\times$ Previous Knowledge on Lycopene & 0.006 & 0.200 & $0.286^{\star \star}$ & 0.133 & 0.148 & 0.148 & 0.021 & 0.204 \\
\hline \multicolumn{9}{|l|}{ Standard deviation of random parameters } \\
\hline HALVE & 0.048 & 0.828 & 0.048 & 0.801 & 0.120 & 0.967 & 0.656 & 0.919 \\
\hline HORMONE & 0.011 & 0.906 & 0.001 & 0.426 & 0.001 & 0.272 & 0.005 & 0.657 \\
\hline NATIVE & 0.007 & 0.311 & 0.003 & 0.238 & 0.016 & 0.393 & 0.002 & 0.362 \\
\hline ENRICHED & $1.697^{\star \star \star}$ & 0.378 & 0.087 & 1.341 & 0.055 & 1.102 & $1.495^{\star \star \star}$ & 0.470 \\
\hline No. of observations & 2,290 & & 2,380 & & 2,420 & & 2,400 & \\
\hline No. of respondents & 229 & & 238 & & 242 & & 240 & \\
\hline Log-likelihood at convergence & $-1,856$ & & $-1,841$ & & $-1,961$ & & $-1,943$ & \\
\hline McFadden's $R^{2}$ & 0.262 & & 0.296 & & 0.262 & & 0.263 & \\
\hline AIC & 3,804 & & 3,774 & & 4,014 & & 3,978 & \\
\hline $\mathrm{BIC}$ & 4,068 & & 4,039 & & 4,281 & & 4,244 & \\
\hline
\end{tabular}

${ }^{*},{ }^{\star *}$, and ${ }^{\star \star \star}$ indicate significance at the $10 \%, 5 \%$, and $1 \%$ levels, respectively. 


\subsection{Willingness to Pay}

Table 6 shows the estimated mean of consumers' WTP for each tomato attribute in the random parameter logit model, with a $95 \%$ confidence interval. The values in the leftmost column of the table indicate the WTP of 309 respondents for whom no information was provided. The right column shows the WTP of 310 respondents with only Information on Quality Improvement. Moreover, the right column shows the WTP of 318 respondents with only Information on Ecological Risk. The rightmost column of the WTP estimates shows the WTP of 296 respondents for whom Information on Both was provided.

Since uncovering how providing information on bumblebees affects WTP for each tomato attribute is the main concern here, the table also includes the results of tests for differences between WTPs. The following five comparisons were made: the no information group compared with the Information on Quality Improvement group, the no information group compared with the Information on Ecological Risk group, the Information on Quality Improvement group compared with the Information on Both group, the Information on Ecological Risk group compared with the Information on Both group, and the no information group compared with the Information on Both group.

First, the HALVE row evidences that respondents were willing to pay an additional mean of 18.24 yen per tomato for reduced pesticide cultivation over conventional cultivation. Compared to conventional cultivation, WTP for tomatoes grown with reduced pesticides showed slightly higher values for respondents with Information on Both, at 23.72 yen per piece. However, it was not possible to confirm a significant difference between the no information group and the Information on Both group.

Next, for hormone-treated tomatoes, respondents were willing to pay a mean of -16.95 yen per tomato over tomatoes pollinated by non-native bumblebees if no information was provided. In the WTP for hormone-treated tomatoes compared to the use of non-native bumblebees as pollinators, respondents with only Information on Ecological Risk and with Information on Both had smaller negative values than those without any information or those with only Information on Quality Improvement. These results indicate that providing consumers with information about the ecological risks posed by non-native bumblebees may reduce their disfavor of hormone-treated tomatoes, perhaps because once they learn about the ecological risks, respondents may believe hormonal treatment is better than using non-native species.

The NATIVE row demonstrates that the respondents appreciate the use of native bumblebees over non-native ones as pollinators, with a mean price increase of 9.81 yen per tomato, even if no information was provided. Moreover, when information on the effect of bumblebees on tomato quality improvement was provided, the value of the price increased by 14.57 yen; meanwhile, when information on the ecological risks posed by non-native species was provided, the value of the price increased by 20.29 yen. When both sets of information were provided, the value of the price increased by 30.64 yen. While the latter information increased WTP for native bumblebees over non-native ones, the former information also increased WTP - it is, therefore, not easy to interpret how respondents' knowledge regarding the effect of bumblebees on improving tomatoes enhances their WTP for native species. However, a comparison between the Information on Ecological Risk group and the Information on Both group shows that such information also increases WTP for pollination by native species.

Furthermore, the ENRICHED row evidences that respondents were willing to pay an additional mean of 8.29 yen for tomatoes with more enriched functional ingredients. No significant differences are evident between WTPs for a rich amount of functional ingredients in tomatoes with and without information. Notably, though insignificant, the higher WTP for tomatoes enriched with lycopene is consistent with the findings of La Barbera, Amato, and Sannino (2016).

In the absence of information, WTP for reduced pesticide cultivation was significantly higher than WTP for pollination by native bumblebees $(P$ value by complete combinatorial test was less 
Table 6. Willingness to pay estimates for each attribute level

\begin{tabular}{|c|c|c|c|c|c|c|c|c|c|}
\hline \multirow[b]{2}{*}{ Attributes } & \multicolumn{4}{|c|}{ WTP estimates } & \multicolumn{5}{|c|}{ Complete combinatorial test for differences between WTPs } \\
\hline & No Information & $\begin{array}{l}\text { Only Information on } \\
\text { Quality Improvement }\end{array}$ & $\begin{array}{l}\text { Only Information } \\
\text { on Ecological Risk }\end{array}$ & Information on Both & $\begin{array}{l}\text { No vs. Only } \\
\text { Quality } \\
\text { Improvement }\end{array}$ & $\begin{array}{l}\text { No vs. Only } \\
\text { Ecological } \\
\text { Risk }\end{array}$ & $\begin{array}{l}\text { Only Quality } \\
\text { Improvement vs. } \\
\text { Both }\end{array}$ & $\begin{array}{c}\text { Only } \\
\text { Ecological Risk } \\
\text { vs. Both }\end{array}$ & $\begin{array}{l}\text { No } \\
\text { vs. } \\
\text { Both }\end{array}$ \\
\hline \multirow[t]{2}{*}{ HALVE } & 18.24 & 21.76 & 17.55 & 23.72 & 0.10 & 0.51 & 0.46 & 0.33 & 0.40 \\
\hline & {$[12.84,23.63]$} & {$[17.71,25.81]$} & {$[13.45,21.66]$} & {$[16.39,31.04]$} & & & & & \\
\hline \multirow[t]{2}{*}{ HORMONE } & -16.95 & -17.00 & -9.48 & -13.59 & 0.54 & 0.00 & 0.00 & 0.00 & 0.02 \\
\hline & {$[-23.25,-10.66]$} & {$[-22.45,-11.55]$} & {$[-14.68,-4.29]$} & {$[-21.28,-5.90]$} & & & & & \\
\hline \multirow[t]{2}{*}{ NATIVE } & 9.81 & 14.57 & 20.29 & 30.64 & 0.00 & 0.00 & 0.00 & 0.00 & 0.00 \\
\hline & {$[4.63,15.00]$} & {$[9.30,19.83]$} & {$[14.38,26.20]$} & {$[20.22,41.05]$} & & & & & \\
\hline \multirow[t]{2}{*}{ ENRICHED } & 8.29 & 7.50 & 4.56 & 6.59 & 0.50 & 0.47 & 0.47 & 0.46 & 0.50 \\
\hline & {$[4.40,12.19]$} & {$[3.64,11.35]$} & {$[0.84,8.27]$} & {$[1.52,11.67]$} & & & & & \\
\hline
\end{tabular}

The value of each WTP is presented with 95\% confidence intervals for the mean in brackets. All values for WTP are in Japanese yen. The value of the complete combinatorial test represents the one-sided significance level of the null hypothesis that both WTPs are equal. 
than 0.01 ). On the other hand, when some information was provided, there was no significant difference between the WTPs. Respondents highly value reduced pesticides because Japanese consumers are relatively familiar with the effects of reduced pesticides on health and the environment. Therefore, by labeling tomatoes with the native bumblebee pollination and, at the same time, making consumers aware of the effects of bumblebees (i.e., tomato quality improvement and ecological risks), it is expected that such labeling will be evaluated as high as that regarding pesticide reduction. This result may affirm the suggestion of a previous study, which compared WTP for environmental consideration and ecosystem consideration in rice production in Japan, that respondents highly evaluate ecosystem considerations because information on ecosystem consideration was highlighted in their questionnaire (Nishimura, Matsushita, and Fujie, 2012).

In contrast to these relationships, in the absence of information, WTP for tomatoes pollinated by native species did not differ from WTP for tomatoes with more enriched functional ingredients. However, by providing information on bumblebees, WTP for the former significantly exceeded WTP for the latter (in each case, the $P$ value by complete combinatorial test was less than 0.01 ). In other words, the respondents showed a certain interest in functional ingredients regardless of whether or not they received the information on bumblebees; however, the WTP for more enriched functional ingredients in tomatoes remained small compared to that for pollination by the native species.

\section{Conclusion}

In this study, whether tomato labeling that advises on pollination methods affects consumer WTP was investigated using a choice experiment conducted with Japanese consumers. This study found that consumers preferred tomatoes pollinated by non-native bumblebees over those cultivated using hormone treatments, even if they were not informed of the tomato quality-enhancing effects of bumblebees. Similarly, it was found that consumers evaluated tomatoes pollinated by native bumblebees higher than those pollinated by non-native bumblebees, even if they were not informed of the ecological risks posed by non-native bumblebees. However, it is not clear whether the WTP premium is significant enough to incentivize growers to switch to native species pollination; economic circumstances and ways of thinking differ among growers. Accordingly, given the possible existence of these price premiums, further research is needed on how tomato growers perceive the premium and how they feel about changing their behaviors.

Moreover, the study found that providing information on the ecological risks posed by non-native bumblebees or on how bumblebee pollination can improve tomato quality compared to hormonal treatment increases the price premiums for tomatoes cultivated with native bumblebees and hormonal treatment over those cultivated with non-native species. This result suggests that, contrary to Oka (2006), providing such information to consumers may incentivize greenhouse tomato growers to refrain from using non-native bumblebees and switch to native species or hormonal treatment. Accordingly, policies that normalize native bumblebee commercial rearing and pollination or hormone treatment may be viable ways to protect Japan's ecosystem.

This study involved several limitations. First, although the respondents were asked about the price of tomatoes, they usually purchased before the experiment, it is important to note that asking them to recall prices in advance may have biased their responses. Future scholarship would do well to examine whether recalling the price in this way affects respondent answers in subsequent choice experiments. Second, this study did not discuss whether hormone-based greenhouse tomato production is economically sustainable; further research is required on this topic.

Financial Support. This work was supported by JSPS KAKENHI Grant Number JP16K00696. 


\section{References}

Aizaki, H. mded: Measuring the Difference Between Two Empirical Distributions, R package version 0.1-2, 2015. Internet site: https://CRAN.R-project.org/package=mded (Accessed July 4, 2020).

Aizaki, H. "Basic Functions for Supporting an Implementation of Choice Experiments in R." Journal of Statistical Software 50, Code Snippet 2(2012):1-24.

Aizaki, H., Y. Nakashima, K. Ujiie, H. Takeshita, and K. Tahara. "Influence of Information About Agrochemicals Provided via Internet-Enabled Mobile Phones on Consumer Valuation of Food." Journal of Agricultural \& Food Information 11,3(2010):209-21.

Aoki, K., K. Akai, and K. Ujiie. "A Choice Experiment to Compare Preferences for Rice in Thailand and Japan: The Impact of Origin, Sustainability, and Taste.” Food Quality and Preference 56,Part B(2017):274-84.

Aoki, K., K. Akai, K. Ujiie, T. Shimmura, and N. Nishino. "The Impact of Information on Taste Ranking and Cultivation Method on Rice Types That Protect Endangered Birds in Japan: Non-Hypothetical Choice Experiment with Tasting." Food Quality and Preference 75(July 2019):28-38.

Banda, H.J., and R.J. Paxton. "Pollination of Greenhouse Tomatoes by Bees." Acta Horticulturae 288(January 1991):194-7.

Carlsson, F., P. Frykblom, and C. Liljenstolpe. "Valuing Wetland Attributes: An Application of Choice Experiments." Ecological Economics 47,1(2003):95-103.

Daşgan, H.Y., A.O. Özdoğan, O. Kaftanoğlu, and K. Abak. "Effectiveness of Bumblebee Pollination in Anti-Frost Heated Tomato Greenhouses in the Mediterranean Basin." Turkish Journal of Agriculture and Forestry 28,2(2004):73-82.

Flanders, R.V., W.F. Wehling, and A.L. Craghead. "Laws and Regulations on the Import, Movement, and Release of Bees in the United States." For Nonnative Crops, Whence Pollinators of the Future? K. Strickler and J. H. Cane, eds. Lanham, MD: Entomological Society of America, 2003.

Fujita, K. “Tomatoes and the Bumble Bee." CBD Business Newsletters 4,1(2009):15.

Goka, K. "Introduction to the Special Feature for Ecological Risk Assessment of Introduced Bumblebees: Status of the European Bumblebee, Bombus terrestris, in Japan as a Beneficial Pollinator and an Invasive Alien Species." Applied Entomology and Zoology 45,1(2010):1-6.

Gosterit, A., and F. Gurel. "The Role of Commercially Produced Bumblebees in Good Agricultural Practices." Scientific Papers: Series D, Animal Science - The International Session of Scientific Communications of the Faculty of Animal Science 61,1(2018):201-4.

Jürkenbeck, K., A. Spiller, and S.G.H. Meyerding. "Tomato Attributes and Consumer Preferences-A Consumer Segmentation Approach.” British Food Journal 122,1(2020):328-44.

Kagome Co., Ltd.-Integrated Report, 2017. Internet site: https://www.kagome.co.jp/english/company/ir/data/report/ (Accessed March 25, 2020).

Katada, M., and H. Tanaka. "Valuing the Low Fertilizer and Agricultural Chemical Rice Produced in Creating a Habitat for Returning Japanese Ibis.” Agricultural Information Research 7,1(2008):6-12 (in Japanese).

Kawano, M. "Economic Evaluation Analysis of Public Awareness of Biodiversity: A Case Study of Alien Species Bombus terrestris (Seibutsu Tayosei Nitaisuru Kokumin Ishiki no Keizai Hyoka Bunseki: Gairai Seibutsu Bombus terrestris wo Jirei ni)." Journal of Global Environmental Studies 1(September 2007):105-43 (in Japanese).

Krinsky, I., and A.L. Robb. "On Approximating the Statistical Properties of Elasticities." The Review of Economics and Statistics 68,4(1986):715-9.

La Barbera, F., M. Amato, and G. Sannino. “Understanding Consumers' Intention and Behaviour Towards Functionalised Food: The Role of Knowledge and Food Technology Neophobia." British Food Journal 118,4(2016):885-95.

Liu, R., Z. Gao, R.M. Nayga Jr., H.A. Snell, and H. Ma. "Consumers' Valuation for Food Traceability in China: Does Trust Matter?" Food Policy 88(October 2019):101768.

Louviere, J.J., D.A. Hensher, and J.D. Swait. Stated Choice Methods: Analysis and Application. Cambridge, UK: Cambridge University Press, 2000.

Lusk, J.L., J. Roosen, and J.A. Fox. "Demand for Beef from Cattle Administered Growth Hormones or Fed Genetically Modified Corn: A Comparison of Consumers in France, Germany, the United Kingdom, and the United States." American Journal of Agricultural Economics 85,1(2003):16-29.

Maples, McK., M.G. Interis, K.L. Morgan, and A. Harri. “Southeastern Consumers' Willingness to Pay for Environmental Production Attributes of Fresh Tomatoes." Journal of Agricultural and Applied Economics 50,1(2018):27-47.

Matsuoka, H., and K. Ujiie. "An Analysis of Consumer Preference for the Eco-friendly Agricultural Products: A Scanner Panel Data Approach.” Journal of Rural Economics 87,3(2015):285-90 (in Japanese).

Matsuura, M. "Pollination of Tomato Plants with the Introduced Bumble Bee, Bombus terrestris." Plant Protection 47,4(1993):173-6 (in Japanese).

Meyerding, S.G.H., N. Trajer, and M. Lehberger. "What is Local Food? The Case of Consumer Preferences for Local Food Labeling of Tomatoes in Germany.” Journal of Cleaner Production 207,10(2019):30-43.

Ministry of Agriculture, Forestry and Fisheries-Situation of Installation of Horticultural Facilities 2016 (Engeiyou Shisetsu no Secchi Tou no Jokyo (H28)), 2018. Internet site: https://www.maff.go.jp/j/seisan/ryutu/engei/sisetsu/haipura/setti_28. html (Accessed March 25, 2020) (in Japanese). 
Ministry of the Environment-Changes in the Operation of Permission to Rear Bombus terrestris Based on Article 5 of the Invasive Alien Species Act (Gairaiseibutsuhou Dai 5 Jo ni Motoduku Bombus terrestris no Shiyo Tou no Kyoka no Unyo no Henko ni Tsuite), 2019. Internet site: http://www.env.go.jp/nature/intro/2outline/attention/file/1_shiyoutoukyoka.pdf (Accessed March 25, 2020) (in Japanese).

Ministry of the Environment and Ministry of Agriculture, Forestry and Fisheries-Policy on the Use of Alternative Species of Bombus terrestris (Bombus terrestris no Daitaishu no Riyo Houshin), 2017. Internet site: http://www.env.go.jp/nature/ intro/2outline/attention/file/seiyouhoushin.pdf or https://www.maff.go.jp/j/press/seisan/kaki/attach/pdf/170421_11-1. pdf (Accessed March 25, 2020) (in Japanese).

Mitsuhata, M. "Pollination of Crops with Bumblebee Colonies in Japan." Honeybee Science 21,1(2000):17-25 (in Japanese).

Mitsuhata, M. Make Good Use of the Bumblebee: Tips for Working Energetic and Longer (Maruhanabachi wo Tsukaikonasu: Yori Genkini Nagaku Hataraitemorau Kotsu). Tokyo: Nosangyoson Bunka Kyokai, 2018 (in Japanese).

Muto, Y., and T. Nishimura. "The Effectiveness of a Voluntary Approach in the Regulation of Economic Utilization of Invasive Alien Species.” Journal of Rural Economics 86,Special Issue(2014):223-8 (in Japanese).

Nishimura, T. "Invasive Alien Species in Agriculture: The Use of Bumblebees for Greenhouse Tomato Pollination in Japan." Annual Report of Research Center for Sustainability and Environment, Shiga University 7,1(2010):29-37 (in Japanese).

Nishimura, T. "Will Participatory Monitoring of a Non-native Bumblebee Species Deter Tomato Producers from Moral Hazard?" Papers on Environmental Information Science 27(November 2013):277-82 (in Japanese).

Nishimura, T., K. Matsushita, and T. Fujie. "Determinants of Price Premium for Ecosystem- and Environment-Friendly Rice: A Case of Sakana no Yurikago Suiden Mai Rice from Shiga Prefecture, Japan." Environmental Science 25,3(2012):204-14 (in Japanese).

Nishimura, T., and Y. Muto. “Tomato Producers' Consciousness of Mutual Monitoring under the Invasive Alien Species Act.” Journal of Rural Economics 91,1(2019):53-8 (in Japanese).

Niwase, I. "Process of Selecting "Invasive Alien Species" for Bombus terrestris and Its Future Response (Bombus terrestris ni Kansuru "Tokutei Gairai Seibutsu" Sentei Sagyo no Keii to Kongo no Taiou)." Facilities and Horticulture (Shisetsu to Engei), 129(April 2005):47-50 (in Japanese).

Oka, T. Environmental Economics (Kankyo Keizaigaku). Tokyo: Iwanami Shoten, 2006 (in Japanese).

Ono, M., and T. Wada. Bumblebee World: Its Biological Basis and Applications (Maruhanabahci no Sekai: Sono Seibutsugakuteki Kiso to Ouyou). Tokyo: Japan Plant Protection Association, 1996 (in Japanese).

Onozaka, Y., and D.T. McFadden. "Does Local Labeling Complement or Compete with Other Sustainable Labels? A Conjoint Analysis of Direct and Joint Values for Fresh Produce Claim.” American Journal of Agricultural Economics 93,3(2011):693-706.

Poe, G.L., K.L. Giraud, and J.B. Loomis. "Computational Methods for Measuring the Difference of Empirical Distributions." American Journal of Agricultural Economics 87,2(2005):353-65.

R Core Team. R: A Language and Environment for Statistical Computing. Vienna, Austria: R Foundation for Statistical Computing, 2019. Internet site: https://www.R-project.org/ (Accessed March 25, 2020).

Revelle, W. psych: Procedures for Psychological, Psychometric, and Personality Research. Evanston, Illinois: Northwestern University. R package version 1.9.12, 2019. Internet site: https://CRAN.R-project.org/package=psych (Accessed March 25, 2020).

Revelt, D., and K. Train. "Mixed Logit with Repeated Choices: Households' Choices of Appliance Efficiency Level." Review of Economics and Statistics 80,4(1998):647-57.

Sarrias, M., and R. Daziano. "Multinomial Logit Models with Continuous and Discrete Individual Heterogeneity in R: The gmnl Package." Journal of Statistical Software 79,2(2017):1-46.

Stevens, T., A.K. Hoshide, and F.A. Drummond. "Willingness to Pay for Native Pollination of Blueberries: A Conjoint Analysis." International Journal of Agricultural Marketing 2,4(2015):68-77.

Teratanavat, R., and N.H. Hooker. "Consumer Valuations and Preference Heterogeneity for a Novel Functional Food." Journal of Food Science 71,7(2006):S533-41.

Train, K.E. Discrete Choice Methods with Simulation, 2nd ed. New York: Cambridge University Press, 2009.

Ujiie, K. “Altruism and Food Consumption: Consumer Evaluation for Attributes Affiliate with Public Dimensions." Journal of Food System Research 20,2(2013):72-82 (in Japanese).

Ujiie, K. "Consumer Preferences and Willingness to Pay for Eco-Labeled Rice: A Choice Experiment Approach to Evaluation of Toki-Friendly Rice Consumption.” Social-Ecological Restoration in Paddy-Dominated Landscapes. Ecological Research Monographs. N. Usio and T. Miyashita, eds. Tokyo: Springer, 2014.

Velthuis, H.H.W., and A. van Doorn. "A Century of Advances in Bumblebee Domestication and the Economic and Environmental Aspects of Its Commercialization for Pollination.” Apidologie 37,4(2006):421-51.

Vergara, C.H. "Environmental Impact of Exotic Bees Introduced for Crop Pollination." Bee Pollination in Agricultural Ecosystems. R.R. James and T.L. Pitts-Singer, eds. New York: Oxford University Press, 2008.

Verneau, F., F. La Barbera, and M. Furno “The Role of Health Information in Consumers' Willingness to Pay for Canned Crushed Tomatoes Enriched with Lycopene.” Nutrients 11,9(2019):2173. 
Washitani, I. “Conservation-Ecological Issues of the Recent Invasion of Bombus terrestris into Japan.” Japanese Journal of Ecology 48,1(1998):73-8 (in Japanese).

Yin, S., M. Chen, Y. Xu, and Y. Chen. “Chinese Consumers' Willingness-to-Pay for Safety Label on Tomato: Evidence from Choice Experiments.” China Agricultural Economic Review 9,1(2017):141-55.

Yabe, M., T. Hayashi, and B. Nishimura. "Economic Analysis of Consumer Behaviour and Agricultural Products Based on Biodiversity Conservation Value." Multifunctional Agriculture, Ecology and Food Security: International Perspectives. J.R. Pillarisetti, R. Lawrey, and A. Ahmad, eds. Lanham, New York: Nova Science Publishers, 2013.

Yoneda, M., K. Tsuchida, and K. Goka. "Ecological Risks of Commercialized Bumblebee and the Invasive Alien Species Act." Japanese Journal of Applied Entomology and Zoology 52,2(2008):47-62 (in Japanese).

\section{Appendix A: Cheap Talk Script}

"Previous studies have shown that respondents tend to choose more expensive products when answering the following questions. With these trends in mind, answer the following questions while imagining the situation in which you make purchases from your wallet with the products in front of you at the store."

Cite this article: Nishimura T (2021). The Effect of Greenhouse Pollination Methods on Consumers' Willingness to Pay for Tomatoes in Japan. Journal of Agricultural and Applied Economics 53, 186-208. https://doi.org/10.1017/aae.2020.33 